\title{
EVALUATION OF LODGING RESISTANCE IN SUGARCANE (SACCHARUM SPP. HYBRID) GERMPLASM RESOURCES
}

\author{
LI, X. ${ }^{1,2 \#}-$ LI, Y. J. ${ }^{2 \#}-$ LIANG, Q. ${ }^{2}-$ LIN, S. H. ${ }^{2}-$ HUANG, Q. Y. ${ }^{2}-$ YANG, R. Z. ${ }^{2}-$ YANG, L. T. ${ }^{1,2^{*}}$ \\ - LI, Y. R. ${ }^{1,2 *}$ \\ ${ }^{1}$ Agricultural College, Guangxi University, Nanning 530005, China
}

${ }^{2}$ Key Laboratory of Sugarcane Biotechnology and Genetic Improvement (Guangxi), Ministry of Agriculture, Guangxi Key Laboratory of Sugarcane Genetic Improvement, Sugarcane Research Center, Chinese Academy of Agricultural Sciences, Sugarcane Research Institute, Guangxi Academy of Agricultural Sciences, Nanning 530007, China

${ }^{\#} \mathrm{Li}, \mathrm{X}$. and Li, Y. J. have contributed equally to this manuscript.

*Corresponding authors

e-mail:litao61@hotmail.com(Litao Yang); liyr@gxaas.net(Yangrui Li)

(Received $3^{\text {rd }}$ Apr 2019; accepted $23^{\text {rd }}$ Apr 2019)

\begin{abstract}
In order to observe the performance of lodging-related traits, evaluate the lodging-resistant ability of different combinations of sugarcane, a field experiment was conducted in 2018. Thirty sugarcane combinations were used as the materials, and the lodging grade, fracture resistance force, basal stem diameter, middle stem diameter and brix were investigated. With the data of lodging classification, the lodging resistance index was established. It was found that the lodging resistance index was significantly and positively correlated with the ratio of basal and middle stem diameters and brix. A cluster analysis was conducted, for the thirty sugarcane combinations by the lodging resistance index, which showed sixteen were lodging resistant, thirteen half-lodging, and two complete-lodging.
\end{abstract}

Keywords: lodging resistance, combination, stem diameter, fracture resistance force, index

\section{Introduction}

Sugarcane (Saccharum spp. hybrid) is the largest sugar crop in China and the world, during the 2017/2018 milling season, the planting area was 1.38 million ha and the sugar yield was 10.48 million tones in China. Guangxi is the first in sugarcane planting area, sugar yield, and economic benefit in Chinese sugar industry (Li et al., 2010). Due to the tall plant and large biomass above ground, lodging occurs very common, which seriously affects the yield and sucrose content in cane, in some areas, the cane yield was reduced by $10 \%$ to $20 \%$ in light, and more than $50 \%$ in severe. The surcrose content was reduced by $15 \%$ to $35 \%$, and the number of millable canes was reduced by 0.8 stalks $/ \mathrm{m}^{2}$ (Li et al., 2018; Singh et al., 2002). Meanwhile, lodging reduces the quality of mechanical harvesting, results in more harvesting loss, and increases broken rate of stools by $24.8 \%$ on average, which seriously hinders the popularization and application of machine harvest in sugarcane (Li, 2010; Mo, 1979) as well as the development of sugarcane industry (Liu and Fan, 2011; Zhang et al., 2010). There have been a lot of research about lodging resistance evaluation of germplasm resources for other crops, such as rice, maize, wheat, etc. (Wang et al., 2014; Kamran et al., 2018; Piñera-Chavez et al., 2016). Up to day, however, there has been no perfect evaluation method for sugarcane lodging at home and abroad, and very few reports about sugarcane lodging research could be referred. Cosidering the changes of climatic and ecological regions and the status of main cultivars, it is necessary to carry out comprehensive and specific 
evaluation and research on lodging resistance of different sugarcane genotypes and the mechanisms in sugarcane lodging resistance (Kimbeng et al., 2000; Singh et al., 1999). This study was done by using thirty sugarcane combinations as materials to study the features of sugarcane lodging, establish classification standards for sugarcane lodging, and evaluate the lodging-resistant ability of the combinations, in order to provide a reference for selection of lodging-resistant parent and varieties in sugarcane.

\section{Materials and methods}

\section{Plant materials}

The tested materials were the seedlings from Sugarcane Research Institute, Guangxi Academy of Agricultural Sciences, Nanning in 2017. Thirty combinations were randomly selected, and the sugarcane variety ROC22 was used as control (Table 1). GT and SWS parents were from Sugarcane Research Institute, Guangxi Academy of Agricultural Sciences. YT and ZZ parents were from Guangzhou Sugarncane Industry Research Institute. YZ and DZ parents were from Sugarncane Research Institute of Yunnan Academy of Agricultural Sciences. CP parents were from USDA Canal Point Sugarcane Field Station. FN, LC and ROC parents were from Fujian Agriculture and forestry university, Sugarcane Research Center of Liucheng and Taiwan Sugarcane Research Institute. C1, Co, FR, PR and NongL were imported from Brazil, Franch, Puerto Rico and Japan, respectively.

Table 1. Sugarcane combinations tested

\begin{tabular}{|c|c|c|c|}
\hline No. & Combination & No. & Combination \\
\hline 142 & CP07-1618×YG22 & 975 & GT05-ym3×LC03-1137 \\
\hline 229 & GT04-112×YC90-33 & 977 & YT94-128×GT09-1163 \\
\hline 283 & GT06-3283×LT07-95 & 981 & SWS09-001×CP92-1641 \\
\hline 289 & NongL8×GT09-1009 & 989 & C1-2003×YZ95-128 \\
\hline 327 & GT04-1023×FN39 & 1124 & GT02-761×YF90-95 \\
\hline 370 & CP07-1618×FN39 & 1245 & GT01-25×CP09-4707 \\
\hline 371 & CP07-1618×LC03-1137 & 1252 & GT05-3661×CP09-4256 \\
\hline 381 & GT05-wm48×GT07-229 & $\mathrm{Y} 12$ & ROC28×YT00-236 \\
\hline 399 & Co1001×GT10-2018 & Y44 & YT00-318×YT93-159 \\
\hline 430 & YZ99-596×GT10-2018 & Y50 & YT01-71×DZ93-88 \\
\hline 506 & GT06-1264×YT96-833 & Y57 & YT91-976×ROC23 \\
\hline 564 & GT02-761×YC07-71 & Y65 & YT93-159×YC07-71 \\
\hline 593 & GT06-3283×YZ06-80 & Y70 & YT94-128×ROC22 \\
\hline 643 & GT02-901×GT06-178 & Y86 & ZZ33×GT92-66 \\
\hline 670 & CP00-1630×GT06-1184 & ROC22 & ROC $5 \times 69-463$ \\
\hline 875 & FR93-865×PR83-1248 & & \\
\hline
\end{tabular}

\section{Experimental site}

The experiment was carried out in Dingdang base of Sugarcane Research Institute Guangxi Academy of Agricultural Sciences in Long'an County. The soil was neutral sandy loam. 


\section{Experiment design}

The seeds of the tested combinations were sowed in late March, 2017, and the seedlings were transplanted to nursery cups in the middle of April when they had two to four leaves. On June $15^{\text {th }}$, they were planted in the field. Sixty nine individual plants were randomly selected in each combination. Repeated planting was carried out for 3 times in randomized block design. Each plot contained one row of $7 \mathrm{~m}$ long, and the space between rows was $1.2 \mathrm{~m}$. Twenty three plants were planted in each plot. Compound fertilizer (N:P:K = 8:6:6) $750 \mathrm{~kg} / \mathrm{ha}$ was applied as the base fertilizer at the time of planting and urea $75 \mathrm{~kg} / \mathrm{ha}$ was dressed at tillering stage.

\section{Investigation index and method}

From November to December, the resistance grade, lodging resistance index, fracture resistance, basal stem diameter, middle stem diameter, and brix were estimated by measuring 21 seedlings in each plot excluding the first and last seedlings to avoid the marginal effect in each row.

Resistance grade: It was estimated by referring to the partition method of Hao et al. (2008) with modification. The classification was done based on the lodging angle formed by the link between the top and the base of the stem, and the perpendicular line of the ground (Table 2).

Lodging resistance index (LRI): It was estimated according to the method of $\mathrm{Li}$ et al. (2012) and Xie et al. (2009). The equation is as follows:

$$
L R I=\Sigma\left(\mathrm{g}_{\mathrm{i}} \times \mathrm{n}_{\mathrm{i}}\right) / \mathrm{N} \times 100 \%
$$

where $\mathrm{n}$ is the number of lodging stalks in a lodging grade, $\mathrm{g}$ is the lodging grade, and $\mathrm{N}$ is the total number of stalks investigated.

Stem diameter: The middle parts of basal and middle stem internode were measured with vernier caliper at mature stage.

Brix: Cane juice was extracted and measure with ATAGO handheld saccharimeter at mature stage.

Fracture resistance force: Ten upright and uniform plants were selected in each row, not including the plants on the sides. A PROSTRATETESTER DIK-7401 was kept vertically to the middle of the stem and push it hard to the plant to form a $45^{\circ}$ included angle. The data showing on the prostrate tester were recorded.

Table 2. The grading standard of sugarcane lodging resistance in field

\begin{tabular}{c|c}
\hline Lodging grade & Lodging angle \\
\hline Grade 1 & $>60^{\circ}$ \\
Grade 2 & $30-60^{\circ}$ \\
Grade 3 & $0-30^{\circ}$ \\
\hline
\end{tabular}

\section{Data analysis}

The data were processed by Excel 2010 and subjected to ANOVA, and mean values were separated using Duncan's multiple range test. All statistical analyses were performed using the DPS 14.15 statistical package. The correlation between 
combinations and lodging indexes were evaluated using Person correlation analysis. The lodging resistance index was used for cluster analysis which was carried out with the method of the distance of $\chi^{2}$ and sum of squares of deviation. The grading standard of sugarcane lodging resistance was made by the observation of the sugarcane lodging and relevant research results (Table 3).

Table 3. The grading standard of sugarcane lodging resistance

\begin{tabular}{c|c|c}
\hline Resistance grade & Lodging resistance index & Lodging level \\
\hline Grade 1 & $1.00-1.60$ & High lodging \\
Grade 2 & $1.61-2.30$ & Middle lodging \\
Grade 3 & $2.31-3.00$ & Erect \\
\hline
\end{tabular}

\section{Results}

\section{Relationship between different agronomic traits and resistance grade}

It data in Table 4 showed that the differences were significant in different lodging types for all the agronomic traits The differences in brix in the erect, half lodging and complete lodging types suggested that the impact of lodging on brix was salient, and lodging would certainly reduce the brix in cane juice. The basal and middle stem diameters also significantly and negatively affected sugarcane lodging. The larger the stem, the higher the lodging resistance was, regardless of middle or basal part. The ratio between basal and middle stem diameter was an important index. Obviously, the stem with consistency from top to base possesses excellent lodging resistance. The stem with thin base and thick middle parts was easy to get lodging.

Table 4. The relationship of different agronomic traits and lodging

\begin{tabular}{c|c|c|c|c}
\hline Type & Brix $\left({ }^{\circ} \mathbf{B X}\right)$ & $\begin{array}{c}\text { Basal stem } \\
\text { diameter }(\mathbf{c m})\end{array}$ & $\begin{array}{c}\text { Middle stem } \\
\text { diameter }(\mathbf{c m})\end{array}$ & $\begin{array}{c}\text { Ratio of middle and } \\
\text { basal stem diameter }\end{array}$ \\
\hline Erect & $19.8 \pm 0.9 \mathrm{a}$ & $237 \pm 21 \mathrm{a}$ & $236 \pm 20 \mathrm{a}$ & $1.00 \pm 0.05 \mathrm{a}$ \\
Half lodging & $19.6 \pm 1.0 \mathrm{~b}$ & $225 \pm 17 \mathrm{~b}$ & $231 \pm 17 \mathrm{~b}$ & $0.98 \pm 0.05 \mathrm{~b}$ \\
Complete lodging & $19.3 \pm 1.2 \mathrm{c}$ & $206 \pm 18 \mathrm{c}$ & $219 \pm 19 \mathrm{c}$ & $0.94 \pm 0.05 \mathrm{c}$ \\
\hline
\end{tabular}

Data in the table are the means of three replicates. Different low case letters in the same column represent the significant difference at $5 \%$ in Duncan's multiple range test

The resistance force test was not effective in this experiment. As shown in Table 5, the differences in repetitions were very significant, but those in combinations were not significant.

Table 5. The relationship of resistance force and different combinations in sugarcane

\begin{tabular}{c|c|c|c|c|c}
\hline Item & Df & Sum Sq & Mean Sq & F value & Pr $(>\mathbf{F})$ \\
\hline Repetition & 2 & 307.5 & 153.8 & 14.85 & $0.000007 * *$ \\
Combination & 30 & 471.9 & 15.7 & 1.52 & 0.0876 \\
Residuals & 56 & 579.7 & 10.4 & & \\
\hline
\end{tabular}

** represent the significance at $1 \%$ levels 


\section{Analysis on relevance between agricultural traits and lodging resistance index}

The lodging index resistance and the diameters of basal and middle stem were highly significantly and positively correlated $\left(\mathrm{r}=0.419^{* *}\right.$ and $\left.0.356^{* *}\right)$, indicating the thicker the stem was, the more lodging resistant the plant was. The lodging resistance index was significantly and positively correlated with the brix, suggesting that erect stalks had higher sugar content in cane. The lodging resistance index showed significantly positive correlation $(\mathrm{r}=0.201 *$ and $\mathrm{r}=0.232 *)$ with the ratio of middle and basal stem diameter, indicating that the sugarcane genotypes with uniform stem were more lodging resistant. Though the correlation coefficients were moderate, they were significant in this study. The larger the ratio of middle and basal stem diameter was, the higher lodging resistance the sugarcane genotypes possessed (Table 6).

Table 6. Correlation coefficients between different traits

\begin{tabular}{c|c|c|c|c|c|c}
\hline Correlation coefficient & $\begin{array}{c}\text { Lodging } \\
\text { resistance index }\end{array}$ & $\begin{array}{c}\text { Resistance } \\
\text { force }\end{array}$ & $\begin{array}{c}\text { The ratio of middle in } \\
\text { basal stem diameter }\end{array}$ & Brix & $\begin{array}{c}\text { Basal stem } \\
\text { diameter }\end{array}$ & $\begin{array}{c}\text { Middle stem } \\
\text { diameter }\end{array}$ \\
\hline Lodging resistance index & 1 & & & & & \\
\hline Resistance force & -0.02 & 1 & & & & \\
\hline $\begin{array}{c}\text { The ratio of middle in } \\
\text { basal stem diameter }\end{array}$ & $0.201^{*}$ & -0.037 & 1 & & & \\
\hline Brix & $0.232^{*}$ & 0.052 & -0.168 & 1 & & \\
\hline Basal stem diameter & $0.419^{* *}$ & $0.294^{* *}$ & 0.432 & 0.093 & 1 & \\
\hline Middle stem diameter & $0.356^{* *}$ & $0.223^{*}$ & -0.049 & 0.19 & 0.87 & 1 \\
\hline
\end{tabular}

$*$ and $* *$ represent the significance at $5 \%$, and $1 \%$ levels, respectively

\section{Cluster analysis}

Systematic cluster analysis was done based on the lodging resistance index, and the results were shown in Figure 1. The 30 tested combinations were divided into three categories, among them, 16 were in level 3, 13 in level 2, and 2 in level 1 (Table 7). GT and YT parents were accounted for $56 \%$ and $44 \%$ in level 3 respectively, and CP parents were accounted for $30 \%$ in level 2 . The control variety ROC 22 belonged to the middle lodging type was classified in level 2 in this study, which was in line with its performance in commercial production.

\section{Discussion}

Three or more classifications were established according to the angle in other crops (Wang et al., 2015; Stamp and Kiel, 2010; Nakajima et al., 2008). By far, there has been no confirmed classification for lodging in sugarcane. In this study, the lodging of 30 sugarcane was classified into three levels, that is, level 1 (lodging), level 2 (halflodging) and level 3 (erect) referring to other crops and sugarcane production reality. Meanwhile, the lodging index was brought up, and supported by the test data. The index could be used to judge the capability of lodging resistance of sugarcane rapidly. In the past, many sugarcane breeders had been deducing the lodging resistance trait by visual observation, and deducing whether the sugarcane was lodging resistant or not according to the approximate growth of sugarcane stalks in the field. But it was difficult for breeders to distinguish the status of some sugarcane genotypes which looked either like 
lodged or erect, unless they were all erect or lodged. If the plants of a clone tended to lodging, which would be classified as complete lodging. With the lodging resistance index established in this study, we can quickly determine the lodging resistance of a clone and greatly improve the efficiency of sugarcane breeding.

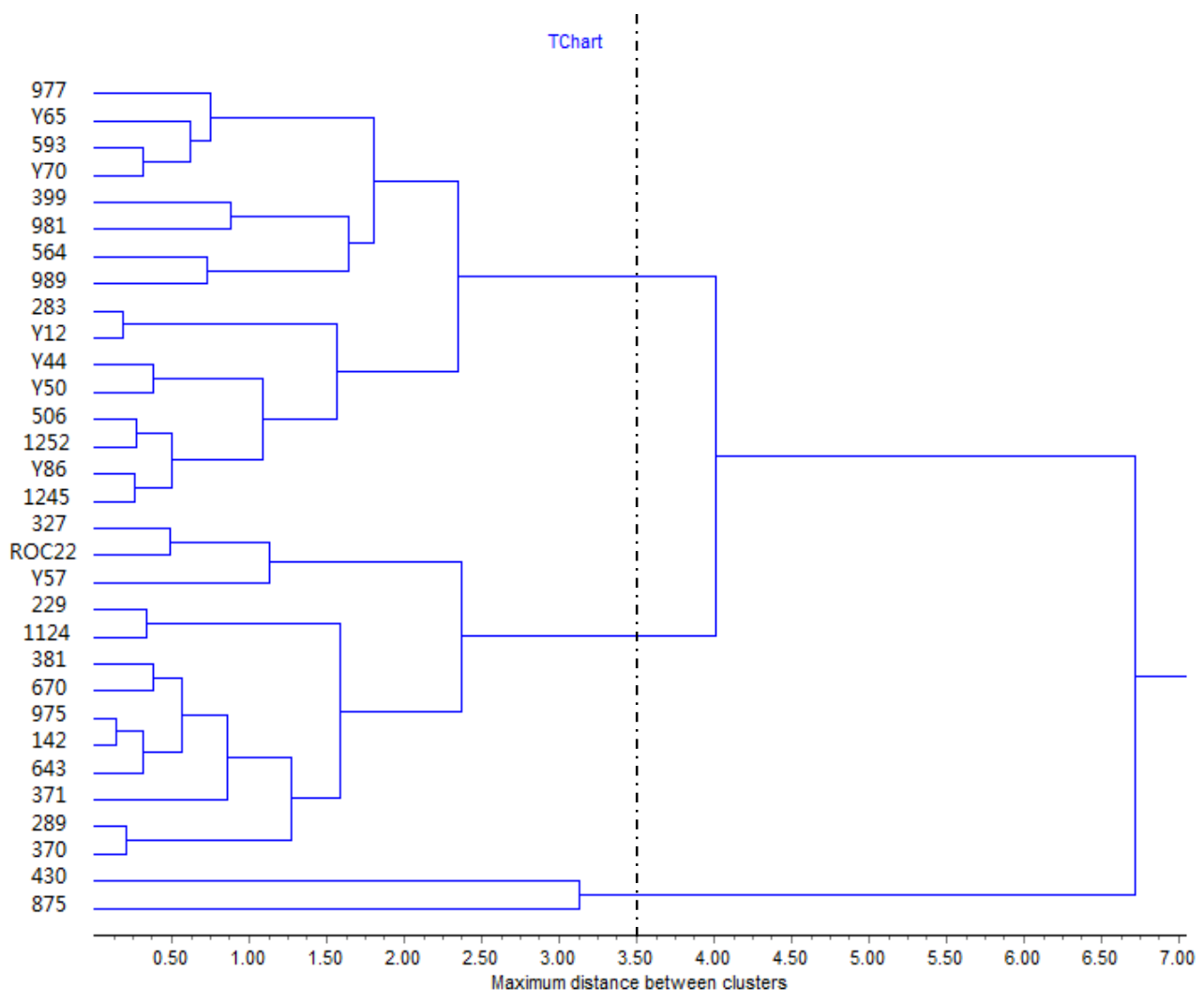

Figure 1. Clustering of lodging for different sugarcane combinations

Table 7. The lodging level of different combinations

\begin{tabular}{c|c|c|c|c|c}
\hline No. & Combination & Level & No. & Combination & Level \\
\hline 977 & YT94-128 $\times$ GT09-1163 & 3 & ROC22 & ROC5 $\times 69-463$ & 2 \\
Y65 & YT93-159 $\times$ YC07-71 & 3 & Y57 & YT91-976 $\times$ ROC23 & 2 \\
593 & GT06-3283 $\times$ YZ06-80 & 3 & 229 & GT04-112 $\times$ YC90-33 & 2 \\
Y70 & YT94-128 $\times$ ROC22 & 3 & 1124 & GT02-761 $\times$ YF90-95 & 2 \\
399 & Co1001 $\times$ GT10-2018 & 3 & 381 & GT05-wm48 $\times$ GT07-229 & 2 \\
981 & SWS09-001 $\times$ CP92-1641 & 3 & 670 & CP00-1630 $\times$ GT06-1184 & 2 \\
564 & GT02-761 $\times$ YC07-71 & 3 & 975 & GT05-ym3 $\times$ LC03-1137 & 2 \\
989 & C1-2003 $\times$ YZ95-128 & 3 & 142 & CP07-1618 $\times$ YG22 & 2 \\
283 & GT06-3283 $\times$ LT07-95 & 3 & 643 & GT02-901 $\times$ GT06-178 & 2 \\
Y12 & ROC28 $\times$ YT00-236 & 3 & 371 & CP07-1618 $\times$ LC03-1137 & 2 \\
Y44 & YT00-318 $\times$ YT93-159 & 3 & 289 & NongL8 $\times$ GT09-1009 & 2 \\
Y50 & YT01-71 $\times$ DZ93-88 & 3 & 370 & CP07-1618 $\times$ FN39 & 2 \\
506 & GT06-1264 $\times$ YT96-833 & 3 & 430 & YZ99-596 $\times$ GT10-2018 & 1 \\
1252 & GT05-3661 $\times$ CP09-4256 & 3 & 875 & FR93-865 $\times$ PR83-1248 & 1 \\
Y86 & ZZ33 $\times$ GT92-66 & 3 & & & \\
1245 & GT01-25 $\times$ CP09-4707 & 3 & & & \\
327 & GT04-1023 $\times$ FN39 & 3 & & & \\
\hline
\end{tabular}


In this study, we identified the relationship between the lodging level and brix and stem diameter in sugarcane. When lodging occurred, the brix was down. Mo (1979) reported that the brix declined after lodging in sugarcane, which is in accordance to the results of this study. In addition, for the first time, this research used the data of the ratio of basal and middle stem diameter. The higher the ratio was, the higher lodging resistance index of sugarcane was. Apparently, they were positively correlated. When the ratio was lower than one, the lodging resistance index decreased and the degree of lodging was significantly higher, caused by the heavy top and light base (Peng, 1988; Feng et al., 2006). In the breeding process of sugarcane or other stalk crops, the breeders preferred to choose the ideal plant type - "tower type" (Liu, 2017). This structure was stable and could minimize losses even in bad weather such as strong wind (Johnson et al., 1998). Especially for the large leafed sugarcane, it is necessary to maintain the stability by selecting the "tower" structure. Therefore, the introduction of the ratio of basal and mid stem diameters would help the breeders to judge sugarcane lodging resistance more comprehensively.

There had been many studies on breeding and selecting resistance traits such as drought resistance, cold resistance and smut resistance by sugarcane germplasm resources (Agboire et al., 2000; Cai et al., 2008; Pan et al., 2006; Zhou et al., 2012). An excellent sugarcane variety was always selected from hundreds of sugarcane combinations (Yang et al., 2011). High yield, high sucrose content, strong ratoon ability and multi-resistance were the breeding targets (Mbuma et al., 2018; Huang et al., 2016; Zhou et al., 2017). However, the most prominent problem encountered in conventional breeding was the narrow genetic basis and insufficient parental innovation, which greatly affects the selection of new breakthrough sugarcane varieties. It is even more difficult to obtain new sugarcane varieties with specific characteristics (Duan et al., 2017; Ramburan et al., 2010). For lodging resistant breeding, it was necessary to have lodging resistant sugarcane germplasm resources (Sengwayo et al., 2018). In this research, based on the lodging resistance index, 30 combinations were classified into three levels, sixteen in level 3, thirteen in level 2, and two in level 1. In the combinations of lodging resistancet, GT and YT parents were accounted for $56 \%$ and $44 \%$ respectively; In the combination of middle lodging, CP parents were accounted for $30 \%$, indicating that the sugarcane varieties (clones) selected and planted in the local climate zone could better adapt to the cultivation environment. In China, the breeders consider more about the effect of lodging on commercial sugarcane production, so they prefer to select the clones with lodging resistance (Yang et al., 2019; Wu et al., 2019). Because of the complete sugarcane mechanization in the USA, the sugarcane breeders mainly considered yield and sugar, and the lodging resistance of sugarcane might be not the main target (Zhou and Li, 2012). Continuous evaluation of the lodging resistance of germplasm resources, statistical analysis of excellent combinations and excellent parents would be helpful to breed lodging resistant sugarcane varieties.

The instrument for measuring the resistance force, DIK7401, did not produce good results in sugarcane. Considering the limit of measurement range of the instrument, and that sugarcane is relatively high and the stem has strong tenacity, the thrust required should be much higher than that for rice (Xiong et al., 2018) and wheat (He, 2018). In the next step, we will consider to use a broader ranged resistance force tester for the study, and NKK-4005 computer-controlled universal testing machine may be used to measure the mechanical indexes of different lodging forms of sugarcane, such as leaf, skin endurance and stem bending resistance (Yang et al., 2016). 


\section{Conclusion}

In this study, lodging grades and lodging resistance index were established for sugarcane. According to the lodging degree, sugarcane lodging could be divided into three grades, that is, grade 1 (complete lodging), grade 2 (half lodging) and grade 3 (erect). The established lodging resistance index could be used to evaluate the lodging resistance of sugarcane quickly. The relationship between lodging and brix and stem diameter was confirmed. The brix in cane juice decreased when lodging occurred. The ratio of basal and mid stem diameters was found highly significantly correlated with the lodging resistance in sugarcane. When the ratio was less than one, the lodging resistance index of sugarcane was low and the lodging degree was obviously heavy. With the lodging resistance index, the thirty combinations used in this study were divided into three categories, sixteen in grade 3, thirteen in grade 2, and two in grade 1.

Acknowledgements. This research was supported by the Fund for the Guangxi Innovation Teams of Modern Agriculture Technology (gjnytxgxcxtd-03), Fund of Guangxi (2016GXNSFBA380138), Fund of Guangxi Science and Technology Base and Special Foundation (AD17195100), Funds of Guangxi Academy of Agricultural Sciences (2015JZ93, 2015YT02; G2014YZ01).

\section{REFERENCES}

[1] Agboire, S., Wada, A. C., Ishaq, M. N. (2000): Evaluation and characterisation of sugar cane germplasm accessions for their breeding values in Nigeria. - Journal of Food Technology in Africa 7(1): 33-35.

[2] Cai, Q., Aitken, K. S., Deng, H. H., Chen, X. W., Mcintyre, C. L. (2008): Verification of the introgression of erianthus arundinaceus germplasm into sugarcane using molecular markers. - Plant Breeding 124(4): 322-328.

[3] Duan, W. X., Huang, Y. X., Zhou, S., Zhang, B. Q., Luo, T., Yang, C. F., Gao, Y. J., Zhang, G. M. (2017): Transmission of parental chromosomes in $\mathrm{F}_{1}, \mathrm{BC}_{1}$ and $\mathrm{BC}_{2}$ progeny between Saccharum spp. hybrid and Narenga porphyrocoma (Hance) Bor. - Chinese Journal of Tropical Crops 38(12): 2201-2005.

[4] Feng, Y. X. (2006): Planting good autumn sugarcane to develop sugar industry. Guangxi Sugar Industry 4: 43-45.

[5] Hao, W. L., Liu, H. X., Zhu, L., Meng, Q. H. (2008): General provisions for methods for determining conditions of agricultural machinery test. - PRC National Standard 65: 2.

[6] He, H. H. (2018): Physical and chemical characteristics related to lodging resistance in wheat. - Wuhan: M. S. Thesis of Huazhong Agricultural University 35: 1023.

[7] Huang, J. Y., Li, X., Tan, F., Tang, S. Y., Wang, L. W., Huang, H. R. (2016): Breeding and characterization of a new sugarcane variety Guitang 49. - Subtropical Agriculture Research 12(2): 73-78.

[8] Johnson, D. E., Dingkuhn, M., Jones, M. P., Mahamane, M. C. (1998): The influence of rice plant type on the effect of weed competition on Oryza sativa and Oryza glaberrima. Weed Research 38(3): 207-216.

[9] Kamran, M., Ahmad, I., Wang, H., Wu, X., Jing, X., Liu, T. (2018): Mepiquat chloride application increases lodging resistance of maize by enhancing stem physical strength and lignin biosynthesis. - Field Crops Research 224: 148-159.

[10] Kimbeng, C. A., Mcrae, T. A., Stringer, J. K., Hogarth, D. M. (2000): Gains from family and visual selection in sugarcane, particularly for heavily lodged crops in the Burdekin region. - Conference of the Australian Society of Sugar Cane Technologists 37: 68-72. 
[11] Li, C. S., Huo, X. J., Wei, S. L., Wei, D., Wei, H. F., Huang, S. M. (2012): Evaluation of 5 banana varieties for resistance to Fusarium wilt. - Journal Of Southern Agriculture 43(4): 449-453.

[12] Li, X., Li, Y. J., Liang, Q., Lin, S. H., Huang, H. R., Huang, Q. Y. (2018): Adaptability of sugarcane clone in Nanning ecological region. - Guangxi Sugar Industry 22: 129-130.

[13] Li, Y. R. (2010): Modern Sugarcane Science. - China Agriculture Press, Beijing, pp. 121122.

[14] Li, Y. R., Mao, C. C., Tang, Q. Z. (2010): Reasons and countermeasures for sugar yield decrease in Asian countries in 2008-2009. - Guangxi Agricultural Science 41(1): 80-84.

[15] Liu, F. X. (2017): Discussion on the reasonable combination of maize plant type and dense planting. - Agricultural Service 22: 103.

[16] Liu, G. L., Fan, H. W. (2011): A better active designfor optimizing grinding parameters of aviation spiral becvel gears. - Joumal of Northwesten Polytechnical University 32(3): 92-97.

[17] Mbuma, N. W., Zhou, M., Merwe, R. V. D. (2018): Evaluating parents for cane yield in sugarcane breeding using best linear unbiased prediction analysis of progeny data derived from family plots. - South African Journal of Plant and Soil 13: 1-8.

[18] Mo, J. Y. (1979): Preliminary analysis of adverse physiological effects of sugarcane lodging - Sugar Industry (12): 22-24.

[19] Nakajima, T., Yoshida, M., Tomimura, K. (2008): Effect of lodging on the level of mycotoxins in wheat, barley, and rice infected with the fusarium graminearum species complex. - Journal of General Plant Pathology 74(4): 289-295.

[20] Pan, S. M., Chen, Y. Q., Wu, J. S., Zhang, M. Q. (2006): ScreenIng and evaluation of the drought resistant gennplasms in sugarcane. - Journal of Jiangxi Agricultural University 28(6): 838-843.

[21] Peng, S. G. (1988): Review of 30 years of sexual crossbreeding of sugarcane in Guangxi. - Southwest Agricultural Journal (3): 15-22.

[22] Piñera-Chavez, F. J., Berry, P. M., Foulkes, M. J., Molero, G., Reynolds, M. P. (2016): Avoiding lodging in irrigated spring wheat. ii. genetic variation of stem and root structural properties. - Field Crops Research 196: 64-74.

[23] Ramburan, S., Paraskevopoulos, A., Saville, G., Jones, M. (2010): A decision support system for sugarcane variety selection in south africa based on genotype-by-environment analyses. - Experimental Agriculture 46(2): 243.

[24] Sengwayo, S., Zhou, M., Labuschagne, M. (2018): Trends in broad-sense heritability and predicted selection gains for the coastal short cycle breeding sugarcane programmes in South Africa. - South African Journal of Plant \& Soil 35(2): 89-99.

[25] Singh, G., Chapman, S. C., Jackson, P. A., Lawn, R. J., Hogarth, D. M. (1999): Yield accumulation in sugarcane under wet tropical conditions - effect of lodging and crop age. - Proceedings of the Australian Society of Sugar Cane Technologists 21: 241-245.

[26] Singh, G., Chapman, S. C., Jackson, P. A., Lawn, R. J. (2002): Lodging reduces sucrose accumulation of sugarcane in the wet and dry tropics. - Australian Journal of Agricultural Research 53(11): 1183-1195.

[27] Stamp, P., Kiel, C. (2010): Root morphology of maize and its relationship to root lodging. - Journal of Agronomy \& Crop Science 168(2): 113-118.

[28] Wang, X. D., Wang, M. Q., Wang, H. X. (2014): Analysis on the relationship between yield components and yield of rice germplasm in cold region. - Heilongjiang Agricultural Sciences 6(3): 153-172.

[29] Wang, Y., Wei, Z. W., Shao, P., Tian, X. H., Wang, X. L., Ma, G. H. (2015): Research status on relationship between culm characteristics and lodging resistance of rice. - Hubei Agricultural Sciences 34: 2054-2057.

[30] Wu, J. Y., Huang, J. J., Ling, Q. P., Chen, Y. S., Zeng, Q. Y., Yang, Z. D., Qi, Y. W., Li, Q. W. (2019): Preliminary identification and evaluation of 12 strains of HoCP series in sugarcane germplasm resources. - Journal of Tropical and Subtropical Botany 1: 53-59. 
[31] Xie, Z. S., Zhang, X., Chen, Y. Y., Luo, S. R., Wei, S. Y. (2009): Assessment of banana germplasm for resistance to fusarium wilt. - Chinese Journal of Tropical Crops 30(3): 362-364.

[32] Xiong, W., Fengying, X. U., Wang, X. (2018): Effect of different nitrogen application rate on rice stem characteristics. - Agricultural Biotechnology 40(2): 56-62.

[33] Yang, R. Z., Li, Y. R., Wang, W. Z., Zhu, Q. Z., Zhou, H., Tang, S. Y. (2011): Evaluation of cold tolerance of sugarcane under drought frost condition. - Agricultural Science \& Technology 24: 1303-1307.

[34] Yang, R. Z., Zhou, H., Lei, J. C., Duan, W. X., Li, Y. R., Tang, S. Y., Li, W. J., Yang, C. F., Gao, Y. J., Zhou, S. (2019): The harvest index of different sugarcane varieties. Sugar Crops of China 41(1): 8-12.

[35] Yang, W., Mo, X. M., Yang, J., Yuan, F. W., Huang, S. C. (2016): Experimental study on the basic parameters of sugarcane on easy lodging period. - Journal of Agricultural Mechanization Research 12: 143-148.

[36] Zhang, X. C., Hu, Y., Yang, Z. J. (2010): Cutting movement analysis of spiral bevel gear based on the tooth generating line. - Jounal of Beijing University of Technology 28(11): 63-67.

[37] Zhou, H., Li, Y. R. (2012): Analysis on sugarcane varieties bred in the United States of America. - Journal of Southern Agriculture 43(5): 570-577.

[38] Zhou, H., Lei, J. C., Gui, Y. Y., Xian, W., Liang, Q., Yang, R. Z., Li, Y. R. (2012): Evaluation on cold tolerance of sugarcane varieties under field conditions. - Journal of Plant Genetic Resources 13(6): 968-973.

[39] Zhou, Z. F., Deng, Y. C., Wang, L. W., Xian, W., Tan, F., Huang, H, R. (2017): Selection and species evaluation of sugarcane variety Guitang 47. - China Seed 2: 62-64. 